\title{
Dynamic Equivalence: Features and Merits
}

\author{
Yinhua Xiang \\ School of Foreign Languages, Chongqing Jiaotong University, Chongqing, China \\ Email: xiangyh6@163.com
}

\begin{abstract}
Euivalence is an essential requirement of translation and the main task of translation activity is to establish equivalence between the source text and the target text. Such being the case, different principles of translation equivalence have been put forward, of which the principle of dynamic equivalence put forward by Nida is the most familiar to and has the greatest influence on Chinese translation circle. It has its own features and boasts a lot of merits, which will be discussed in this paper.
\end{abstract}

Index Terms - dynamic equivalence, features, merits

\section{FEATURES OF THE PRINCIPLE OF DYNAMIC EQUiVALENCE}

In Toward a Science of Translating, Nida first put forward the principle of dynamic equivalence which he defines as "the relationship between receptor and message should be substantially the same as that which existed between the original receptors and the message" (Nida,1964, p.159). Following this principle, he defines D-E (dynamic-equivalence) translation as "the closest natural equivalent of the source-language message" (Nida, 1964, p.166). To discuss the merits of this principle, we must first know about the essential features of this principle and D-E translation.

As Nida himself points out, the essential features of D-E translation consists of the following points:

(1) equivalent, which points toward the source-language message.

(2) natural, which points toward the receptor language

(3) closest, which binds the two orientations together on the basis of the highest degree of approximation (Nida, 1964).

All these points aim at arousing "similar response" between the source text readers and the target text readers.

\section{A. Equivalent}

As mentioned above, this aims at reproducing the message of the original text. This is the basic requirement of D-E translation, as is with any other kind of translation. That is say, to produce a D-E translation, the translator must aim primarily at conveying the meaning of the original text, and to do anything else is essentially wrong to his task as a translator, because translation is basically a kind of communication (Nida and Taber, 1982).

\section{B. Natural}

A D-E translation is directed primarily toward the similarity of response. To achieve this purpose, the translation must be natural, for it is of great importance to arousing in the target readers a response similar to that of the original readers. To be natural, the equivalent forms should not be "foreign" either in terms of form, or in terms of meaning, which means that the translation should not reveal any signs of its non-native source (Nida, 1975) . Nida stresses that naturalness in a D-E translation must fit these three aspects: (1) the receptor language and culture as a whole, (2) the context of the particular message, (3) the receptor-language audience ((Nida, 1964). He further remarks:

The best translation does not sound like a translation.... [It should not] exhibit in its grammatical and stylistic forms any trace of awkwardness or strangeness.... [It] should studiously avoid 'translationese'-- formal fidelity, with resulting unfaithfulness to the content and the impact of die message (Nida and Taber, 1982).

\section{Closest}

"Closest" here is of a double nature. On the one hand, it indicates that equivalence in translation can never be absolute identity, because "loss occurs in all forms of communication, whether it involves translation or not" (Bassenet and Lefvere, 1990, p.35). It can only be an approximation, because no two languages are identical, either in the meanings given to corresponding symbols or in the ways in which such symbols are arranged in phrases and sentences. Therefore, the total impact of a translation may be reasonably close to the original, but there can be no identity in detail.

On the other hand, since equivalence in translation is just a kind of approximation, not absolute identity, it naturally results in the possibility to establish equivalence between the source text and the target text on various degrees or in different aspects. However, it is the highest degree that a D-E translation is expected to strive for. In other words, though loss of meaning is inevitable, the translator should try his best to reduce it to the minimum.

\section{Similar Response}

This is the principal aim of the D-E translation and all the above three points are directed to it. The term "response" here refers to the way in which receptors of a text understand the text, including the effect the text produces on them 
while "similar response" involves a comparison of two relations: the relation of the target text readers to the target text should be substantially the same to that of the source text readers to the source text. That is to say, the target text readers must not only know how the source text readers must have understood the content of the text, but they should also be able to appreciate some of the impact and appeal which such a text must have had for the source text readers (Jin Di and Nida, 1984).

\section{Merits OF THE PRINCIPLE OF DYNAMIC EQUIVALENCE}

As is known to all, translation in essence is a kind of communication, and its main task is to let the target reader understand the meaning of the original text. Whether a translation is good or not depends largely on whether the target reader understands the original message adequately. However, traditionally, the adequacy of translation is judged only on the basis of the correspondence in words and grammar between the source and target languages, and this is sometimes misleading (Nida, 1993). Since translating means communication, evaluating the adequacy of a translation cannot stop with a comparison of corresponding lexical meanings, grammatical classes, and rhetorical devices. In short, it cannot stop with a comparison of the verbal forms of the source and target texts. Instead, it should take into consideration the reader's response and comparison should be made between "the way in which the original receptor understood and appreciated the text and the way in which receptors of the translated text understand and appreciate the translated text" (Nida, 1993 p.116).

It has a lot of merits to take into consideration the readers' response and focus on the similarity between the response of the source text readers and that of the target text readers, which include the following aspects:

\section{A. Rationality of Taking into Consideration the Reader's Response}

Since translation is mainly intended for its readers to understand, quite naturally, we should take into consideration how the readers interpret the translation, namely, their response to the target text, and compare it with that of the source text readers to the source text. Only when the response of the source text readers and that of target text readers are similar can we say that the translation is adequate. If we do not take into consideration the readers' response when judging the adequacy of a translation, it is often misleading. As we know, sometimes what seems to be equivalent translation of the original text in terms of lexical, grammatical features may actually distort the meaning. This may be indicated in the following example.

She is a cat.

A. 她是一只猫。

B. 她是一个包藏祸心的女人。（Ke Ping, 1998）

Superficially, Version A is equivalent to the original sentence in almost every aspect, such as words, grammatical structure, etc. However, it is not equivalent in terms of meaning, and yet, the basic task of an adequate translation is nothing but to convey the meaning of the original. According to Western culture, the cat is a devil incarnation and the guard of witches in Middle Ages. The word "cat" is often used to refer to a nasty woman or a badly behaved and hot-tempered woman. Because of this cultural background, the original reader simply does not interpret "she is a cat" literally. Instead, when he reads it, his primary response to it is that "she is wicked." To arouse this similar response, version B puts it as "她是一个包藏祸心的女人" and it is equivalent to the original sentence in real sense.

Professor Jin Di expresses the same opinion on the rationality of taking into consideration the readers' response when he remarks as follows:

Most earlier approaches to translation have focused attention upon the relationship of the source text to the target text, whether in terms of form or content. The concept of dynamic equivalent translating introduces an important new dimension, namely, the relationship of receptors to the respective texts.... [It] deals not merely signs as signs, but focuses on the ways in which verbal signs have meaning for receptors. It is really within such a context that discussions of transnational adequacy and acceptability make sense (Jin Di and Nida, 1984).

In short, taking into consideration the readers' response helps to reproduce the original message adequately and guarantee equivalence between the source text and the target text in real sense.

\section{B. Avoiding the Debate over Literal Translation versus Free Translation}

Whether to translate literally or freely is an issue that has long been debated in the translation circle. Some scholars argue for literal translation while others argue for free translation. It seems that the two views will never reconcile with each other. However, it is no use arguing which is better, since literal translation and free translation both have their validity and limitations. Instead, it is more helpful, in the author's opinion, to deal with this issue from a different perspective and provide a principle of translation that can well combine them.

In a sense, the principle of dynamic equivalence may serve as an effective means to turn aside the debate. Since it focuses on the similar response, any kind of translation, either literal or free, is adequate, so long as it can arouse the similar response. Thus, the debate over literal translation versus free translation tends to be useless, and the choice between them depends on which can better bring about the "closest natural equivalent" and elicit "substantially the same response". 
Sometimes, a literal translation may be quite adequate and can arouse similar response in the target readers to that of the original readers, for sometimes languages have similar plays on words, almost identical proverbs, or parallel rhetorical patterns. Generally speaking, it is more likely to produce the "closest natural equivalent" and arouse "substantially the same response" by means of a free translation. However, we must be careful with the degree of "freedom" in free translating. Free translation should aim at better conveying the message of the original and eliciting similar response. It should not be produced at the sacrifice of the original message. That is because the basic task of translation is to convey the message of the source text. A translation that does not convey the message of the source text is by no means a good translation; at most, it may only be a good creation or rewriting.

\section{Freeing the Translator from the Binding of the Original Verbal Form and Increasing Translatability}

Languages differ from each other, and each language has its own peculiarities. Sometimes the ways of using language are peculiar to a certain language. In this case, if the translator focuses on the original verbal form, he is usually incompetent. However, if he turns aside from the verbal form and focuses on the similar response, he can sometimes "crack the nut". Let's see the following example:

But it was not from Henry; it was a message from the desk clerk. She read: "9:20. Mr. Remsee fone. You lost pkg in his ownership. He bid you stop before tiring." She judged the last word was intended to be "retiring".

但那不是亨利写的, 而是前台服务员留下的条子。她读到: 九点二十分, 拉姆西先生来电话, 说你把包裹落 在他家。他让你旧寝前到他哪儿去。她判断“旧寝”两个字可能是“就寝”。（华胄译）

In the original, in order to indicate that the desk clerk is not well educated, the author deliberately misspells some words, such as "Remsee" for "Ramsey" (拉姆西), "fone" for "phoned", and misuses "stop" for "stop by" which means “drop by” (顺便走访). As a matter of fact, this kind of meaning is rather difficult to reproduce if one focuses on the verbal form. In the translation, the translator gives up the verbal form and, aiming at producing the similar response in the target readers as that of the original readers, he deliberately employs“旧寝”for “就寝”which helps to arouse the similar response and at the same time conveys the main content. Therefore, the whole version is adequate.

\section{CONCLUSION}

Translation in essence is a kind of communication, the basic requirement of which should be to establish equivalence between the source text and the target text. So far, different principles of translation equivalence have been put forward, of which the principle of dynamic equivalence put forward by Eugene A. Nida has more merits. It focuses on producing "the closest natural equivalent" of the source language message and aims at eliciting "substantially the same response" between source text readers and target text readers. Since it emphasizes similar response between source text readers and target text readers, any kind of translation is adequate, so long as it can produce similar response on the side of readers. Consequently, it helps to free the translator from the binding of the linguistic form of the source text, thus increasing translatability to a certain degree.

\section{REFERENCES}

[1] Bassenet, Susan \& Andre Lefevere, eds. (1990). Translation: history \& culture. London: Casell.

[2] Catford, J. C. (1965). A Linguistic Theory of translation. London: Oxford University Press

[3] Gentzler, Edwin. (1993). Contemporary translation theories. London: Routledge.

[4] Jin Di \& Eugene A. Nida. (1984). On translation: with special reference to Chinese and English. Beijing: China Translation \& Publish Corporation.

[5] Ke Ping. (1998). English-Chinese and Chinese-English translation course. Beijing: Peking University Press.

[6] Nida, Eugene A.. (1964). Toward a science of sranslating. Leiden: E. J. Brill.

[7] Nida, Eugene A. (1975). Language structure and translation. Stanford: Stanford University Press.

[8] Nida, Eugene A. (1993). Language, culture and translating. Shanghai: Shanghai Foreign Language Education Press.

[9] Nida, Eugene A. \& Charles R. Taber. (1982). The theory and practice of translation. Leiden: E. J. Brill.

[10] Nord, Christian. (1997). Translating as a purposeful activity. Manchester: St. Jerome.

Yinhua Xiang was born in Chongqing, China in 1966. He received his M.A degree in translation from Sichuan International Studies University, China in 2000.

$\mathrm{He}$ is currently a lecturer in the School of Foreign Languages, Chongqing Jiaotong University, Chongqing, China. His research interests include theory and practice of translation, teaching theory and method of English and lexicology. 